\title{
Cobalt-Dispersed Reduced Graphene Oxide Nanocomposite for the Selective Electrochemical Detection of Methyl Nicotinate ${ }^{\dagger}$
}

\author{
Pallab Kumar Bairagi ${ }^{1}$, Arpit Goyal ${ }^{1}$ and NishithVerma ${ }^{1,2, *}$ \\ 1 Department of Chemical Engineering, Indian Institute of Technology Kanpur, Kanpur-208016, India; \\ pallabchemengg2011@gmail.com (P.K.B.); goarpit@live.com (A.G.) \\ 2 Center for Environmental Science and Engineering, Indian Institute of Technology Kanpur, Kanpur-208016, \\ India \\ * Correspondence: nishith@iitk.ac.in; Tel.: +91-512-259-6767 \\ + Presented at 7th International Symposium on Sensor Science, Napoli, Italy, 9-11 May 2019. \\ Published: 10 July 2019
}

\begin{abstract}
Methyl nicotinate (MN) is an important tuberculosis biomarker, and can be effectively measured using electrochemical methods. In this study, we have developed a novel N-doped phenolic polymer nanocomposite in situ dispersed with reduced graphene oxide and cobalt (Co)-nanoparticles as a sensor electrode $\left(\mathrm{Co}-\mathrm{rGO} / \mathrm{P}_{\mathrm{C}}\right)$. Co-nanoparticles were used for the $\mathrm{MN}$ recognition. Carbonization was performed for the reduction of GO and the synthesis of Co-nanoparticles. The prepared electrode materials were characterized using SEM, EDS, EIS, and $\mathrm{CV}$. Tested using differential pulse voltammetry, $\mathrm{Co}-\mathrm{rGO} / \mathrm{P}_{\mathrm{C}}$ showed its applicability $(\mathrm{RSD}<6 \%$ ) over $0.05-20.0 \mathrm{mg} \mathrm{L}^{-1} \mathrm{MN}$ concentration with high sensitivity $(\mathrm{S} / \mathrm{N}$ ratio $=3)$. The present method and materials can also be used for the development of sensors for the other biomarkers.
\end{abstract}

Keywords: electrochemical; methyl nicotinate; graphene oxide; Co-nanoparticles

\section{Introduction}

Tuberculosis (TB), a chronic bacterial disease caused by Mycobacterium tuberculosis, affects millions of people, mainly in developing countries [1]. Several antigen-based electrochemical biosensors were developed for detecting TB, showing high selectivity and sensitivity [2], but these sensors are lack of high reusability and repeatability. Efforts to prepare an electrochemical recognition element for methyl nicotinate (MN) produced by Mycobacterium tuberculosis [3] have shown excellent outcomes using Co-nanoparticle (NP) as the recognition element. The method was, however, not explored much for diagnosing TB. Graphene-based material has been widely used as electrode materials, among which reduced graphene oxide (rGO) is easy to synthesize and disperse in a liquid [4]. Therefore, a metal-rGO-polymer network may open a new platform for the detection of TB.

Here, we have developed a novel rGO and $\mathrm{N}$-doped amorphous carbon nanocomposite $\left(\mathrm{rGO} / \mathrm{Pc}_{\mathrm{c}}\right)$ as an electrode material. The sensor $(\mathrm{Co}-\mathrm{rGO} / \mathrm{Pc})$, prepared by dispersing Co-NPs in electrode was used for measuring MN using Co NP-MN interactions. The prepared electrode materials were characterized using different physico-chemical and electro-chemical characterizations. Differential pulse voltammetry (DPV) and cyclic voltammetry (CV) were employed for testing the applicability of the prepared Co-rGO/Pc sensor for measuring $\mathrm{MN}$ in the synthetic test solution. 


\section{Materials and Methods}

MN was purchased from Tata Chemicals (India). Rest all chemicals were supplied by Merck (India). All electrochemical experiments were performed using a potentiostat (AUTOLAB 302N) in a three electrode assembly with a $\mathrm{Pt}$ rod and an $\mathrm{Ag} / \mathrm{AgCl}$ as auxiliary and reference electrode, respectively. Graphene oxide (GO) was prepared by oxidizing graphite, using Hummers' method [5]. Approximately $1 \mathrm{~g}$ of the prepared $\mathrm{GO}$ was dispersed in a $50 \mathrm{~mL}$ cobalt nitrate $\left(\mathrm{Co}\left(\mathrm{NO}_{3}\right)_{2} \cdot 6 \mathrm{H}_{2} \mathrm{O}\right)$ solution $(0.4 \mathrm{M})$ using sonication, and the solid-liquid suspension was centrifuged ( $8000 \mathrm{rpm})$ followed by drying at room temperature $\left(30^{\circ} \mathrm{C}\right)$. Next, a conductive phenol/formaldehyde copolymer (N-doped) was prepared according to the previous studies $[4,6]$. At the incipience of gel formation, $1 \mathrm{~g}$ cobalt nitrate-dispersed GO was mixed into the mixture. After $10 \mathrm{~min}$ the gel was cast on Petri dish (made of Teflon) and dried at $60^{\circ} \mathrm{C}$. The dried film was cut into rectangular shapes and used as working electrode. The films were heated at $600{ }^{\circ} \mathrm{C}$ under $\mathrm{H}_{2}$ gas flow to prepare the electrode $\left(\mathrm{Co}-\mathrm{rGO} / \mathrm{P}_{\mathrm{c}}\right)$ via carbonization and reduction. Some electrode samples were made without $\mathrm{Co}$ and $\mathrm{rGO}$, and termed as $\mathrm{P}^{*} \mathrm{C}$ for the comparison purposes.

\section{Results and Discussion}

\subsection{Surface Morphology}

Electronic images of the prepared GO and the Co-rGO/Pc sensor were acquired using a Field Emission Scanning Electron Microscopy (FE-SEM) and are presented in Figure 1a,b. SEM image corresponding to GO (Figure 1a) showed the presence of few thin layers in the material, confirming the GO formation. Figure $1 \mathrm{~b}$ showed a porous and smooth uniform surface of Co-rGO/Pc. EDS data measured for the Co-rGO/Pc confirmed the presence of $\mathrm{Co}$ in the sensor and N-doping (Figure 1c).

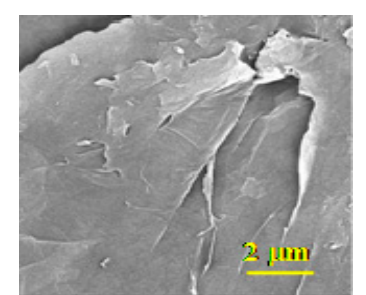

(a)

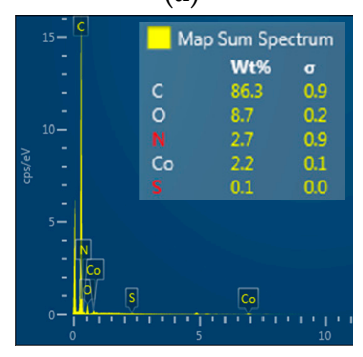

(c)

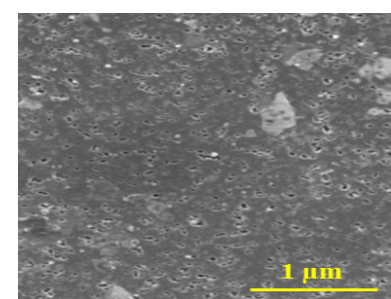

(b)

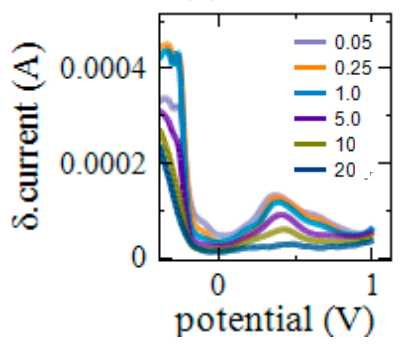

(d)

Figure 1. SEM images of (a) GO and (b) Co-rGO/Pc, (c) EDS data of Co-rGO/Pc, and (d) DPV measurement data in different concentration of $\mathrm{MN}\left(\mathrm{mg} \mathrm{L}^{-1}\right)$ measured with Co-rGO/Pc sensor.

\subsection{Electrochemical Characterization and Measurements}

Different impedance components, namely, solution resistance (Rs) and charge transfer resistance (Rct) of $\mathrm{P}_{\mathrm{C}}^{*}$ and $\mathrm{Co}-\mathrm{rGO} / \mathrm{Pc}_{\mathrm{C}}$ were measured using electrochemical impedance spectroscopy (EIS) at $0.0 \mathrm{~V}$, and the data are summarized in Table 1. A lesser value for both, Rs and Rct were measured in Co-rGO/Pc $\left(\sim 20\right.$ and $10 \Omega$, respectively), compared to $\mathrm{P}^{*}{ }_{C}$, confirming an increase in the electrical conductivity of the electrode material because of the Co NPs and rGO. 
$\mathrm{CV}$ method was used to study the potential driven $\mathrm{MN}$ measurements over -1.0 to $+1.0 \mathrm{~V}$ at a scan rate of $10 \mathrm{mV} \mathrm{s}^{-1}$ using Co-rGO/Pc, immersed in $\mathrm{MN}$ solution (50 mg L-1, $\mathrm{pH}$ 6.0). A couple of peaks near $+0.12 \mathrm{~V}$ (cathodic) and $-0.45 \mathrm{~V}$ (anodic) was observed (Table 1), attributed to the reduction and oxidation of surface adsorbed MN molecules. However, the anodic peak current was observed to be significantly small in both, $\mathrm{rGO} / \mathrm{P}_{\mathrm{c}}$ (data not shown) and $\mathrm{P}^{*} \mathrm{c}_{\text {, indicating the }}$ electro-catalytic effects of Co NPs in oxidation.

Table 1. Measured electrochemical parameters.

\begin{tabular}{ccccc}
\hline \multirow{2}{*}{ Electrodes } & \multirow{2}{*}{$\boldsymbol{R s}(\boldsymbol{\Omega})$} & \multirow{2}{*}{$\boldsymbol{R c t}(\boldsymbol{\Omega})$} & \multicolumn{2}{c}{ Potentials for MN Measurements } \\
\cline { 4 - 5 } & & & Cathodic (V) & Anodic (V) \\
\hline $\mathrm{P}^{*}{ }_{\mathrm{C}}$ & $\sim 23$ & $\sim 17$ & absent & -0.55 \\
\hline Co-rGO/PC & $\sim 20$ & $\sim 10$ & 0.12 & -0.45 \\
\hline
\end{tabular}

\subsection{DPV Measurements}

Measurements were taken between -1.7 to $+1.0 \mathrm{~V}$ at a scan rate of $10 \mathrm{mV} \mathrm{s}^{-1}$ using Co-rGO/Pc sensor immersed in $40 \mathrm{~mL} \mathrm{MN}$ solutions of different concentrations over 0.0001 and $50 \mathrm{mg} \mathrm{L}^{-1}$. A maximum peak current was observed near $0.4 \mathrm{~V}$, indicating the oxidation by Co NPs (Figure 1d). The current value was observed to be steadily decreasing with increasing concentrations over 0.05 to $20 \mathrm{mg} \mathrm{L}^{-1}$. The data clearly revealed that the MN molecules were adsorbed on the surface of the electrode via a complex formation when the Co NPs were present, and the free Co NPs were oxidized at $0.4 \mathrm{~V}$. With increasing $\mathrm{MN}$ concentrations, the surface coverage increased upto a particular value, and therefore, a decrease in current was observed corresponding to the oxidation by Co.

\section{Conclusions}

The Co-rGO/Pc sensor electrode developed in this study showed promising electrochemical characteristics, viz. low values of the resistances. The prepared electrode was successfully tested for measuring MN with Co NPs functioning as the recognition element. The presence of Co NPs in the material also enhanced the conductivity of the electrode. The prepared sensor showed its applicability over a wide concentration range $\left(0.05-20 \mathrm{mg} \mathrm{L}^{-1}\right)$ for the precise and accurate measurement of $\mathrm{MN}$ for diagnosing $\mathrm{TB}$.

Author Contributions: P.K.B. and A.G. have equal contributions in performing the experiments and data analysis in this study. P.K.B. wrote the manuscript. The study was performed under the supervision of N.V.

Conflicts of Interest: The authors declare no conflict of interest.

\section{References}

1. Abdelwahab, A.E. Immonologocal and molecular diagnosis of mycobacterium tuberculosis between two enviromentally different regions. Aced. J. Inc. 2009, 1, 1-8.

2. Li, L.; Yuan, Y.; Chen, Y.; Zhang, P.; Bai, Y.; Bai, L. Aptamer based voltammetric biosensor for Mycobacterium tuberculosis antigen ESAT-6 using a nanohybrid material composed of reduced graphene oxide and a metal-organic framework. Microchim. Acta 2018, 185, 379-387.

3. Bhattacharyya, D.; Smith, Y.R.; Mishra, M.; Mohanty, S.K.; Electrochemical detection of methyl nicotinate biomarker using functionalized anodized titania nanotube arrays. Mater. Res. Express 2015, 2, 025002.

4. Bairagi, P.K.; Gupta, G.S.; Verma, N. Fe-enriched clay-coated and reduced graphene oxide-modified $\mathrm{N}$-doped polymer nanocomposite: A natural recognition element-based sensing electrode for DNT. Electroanalysis 2018, 30, 535-544. doi:10.1002/elan.201800585. 
5. Hummers, W.S.; Offeman, R.E. Preparation of graphitic oxide. J. Am. Chem. Soc. 1958, 80, 1339.

6. Khare, P.; Ramkumar, J.; Verma, N. Carbon nanofiber-skinned three dimensional Ni/carbon micropillars: High performance electrodes of a microbial fuel cell. Electrochim. Acta 2016, 219, 88-98.

(C) 2019 by the authors. Licensee MDPI, Basel, Switzerland. This article is an open access article distributed under the terms and conditions of the Creative Commons Attribution (CC BY) license (http://creativecommons.org/licenses/by/4.0/). 